James Madison University

JMU Scholarly Commons

Senior Honors Projects, 2020-current

Honors College

$5-9-2020$

\title{
A pilot study on the impact of teaching assistant led CS1 study sessions using Peer Instruction
}

Megan E. Gilbert

Follow this and additional works at: https://commons.lib.jmu.edu/honors202029

Part of the Curriculum and Instruction Commons, Educational Methods Commons, Other Computer Sciences Commons, and the Science and Technology Studies Commons

\section{Recommended Citation}

Gilbert, Megan E., "A pilot study on the impact of teaching assistant led CS1 study sessions using Peer Instruction" (2020). Senior Honors Projects, 2020-current. 28.

https://commons.lib.jmu.edu/honors202029/28

This Thesis is brought to you for free and open access by the Honors College at JMU Scholarly Commons. It has been accepted for inclusion in Senior Honors Projects, 2020-current by an authorized administrator of JMU Scholarly Commons. For more information, please contact dc_admin@jmu.edu. 
A Pilot Study on the Impact of Teaching Assistant Led CS1 Study Sessions using Peer Instruction

An Honors College Thesis Presented to

the Faculty of the Undergraduate

College of Integrated Science and Engineering

James Madison University

by Megan Elizabeth Gilbert

May 2020

Accepted by the faculty of the Computer Science department, James Madison University, in partial fulfillment of the requirements for the Honors College.

FACULTY COMMITTEE:

Thesis Advisor: Dee A. B. Weikle, Ph.D. Associate Professor, Computer Science

Reader: Michael S. Kirkpatrick, Ph.D. Associate Professor, Computer Science

Reader: Christopher S. Mayfield, Ph.D. Associate Professor, Computer Science

Reader: Angela W. Webb, Ph.D.

Assistant Professor, MSME
HONORS COLLEGE APPROVAL:

Bradley R. Newcomer, Ph.D.

Dean, Honors College

\section{PUBLIC PRESENTATION}

This work is accepted for presentation, in part or in full, at James Madison University on April 24, 2020. 
Copyright (c) 2020 by Megan Gilbert All Rights Reserved 


\section{Dedication}

I dedicate this dissertation to my advisor Dr. Weikle for all of her support, help, guidance, and most of all for believing in this project; and to Dr. Michael Kirkpatrick for helping design the study, Dr. Chris Mayfield for support through the IRB process and data collection, and Dr. Kenn Barron for specific suggestions for motivating attendance; and finally to my friends, family, and everyone involved in this project, for their continued support and encouragement. 


\section{Table of Contents}

List of Tables . . . . . . . . . . . . . . . . . . . . . . . 6

List of Figures . . . . . . . . . . . . . . . . . . . . . . . . . . 7

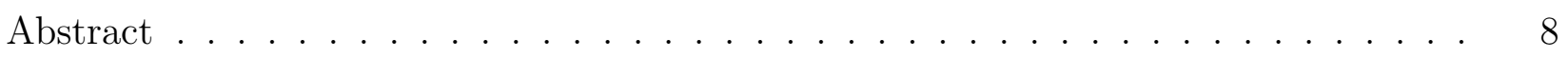

1 Introduction . . . . . . . . . . . . . . . . . . . . 10

1.1 Purpose and Objectives . . . . . . . . . . . . . . . 10

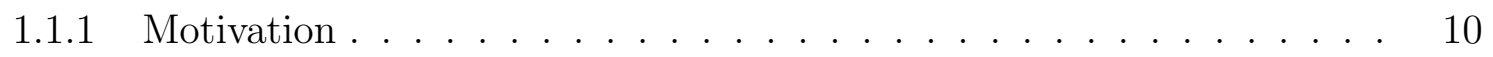

1.1 .2 Goals/Overview . . . . . . . . . . . . . . . . 13

1.2 Background: Choosing a Teaching Pedagogy . . . . . . . . . . . . . . . 14

1.2.1 Peer Led Team Learning . . . . . . . . . . . . . . . . . . . 14

1.2 .2 Process Oriented Guided Inquiry Learning . . . . . . . . . . . . . . . 16

1.2.3 Pair Programming . . . . . . . . . . . . . 16

1.2.4 Peer Instruction . . . . . . . . . . . . . . . . . . . . . 17

1.3 Related Work . . . . . . . . . . . . . . . . . . . 17

2 Implementation . . . . . . . . . . . . . . . . . . . . . 20

2.1 Study Session Design . . . . . . . . . . . . . . . . . . 20

2.1.1 Session Overview . . . . . . . . . . . . . . . . 20

2.1.2 Session Schedule . . . . . . . . . . . . . . . . . . . . 21

2.1.3 Implementing Peer Instruction . . . . . . . . . . . . . . . . . . . . 21

2.1.4 Creating Peer Instruction Questions . . . . . . . . . . . . . . 23

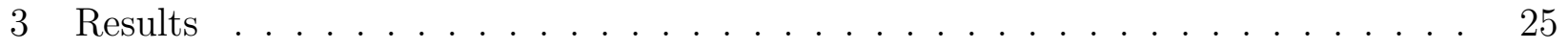

3.1 Participant Attendance and Demographics . . . . . . . . . . . . 25

3.1.1 Attendance ......................... 25

3.1 .2 Demographics . . . . . . . . . . . . . . . . . 26

3.2 Evaluating Content Retention . . . . . . . . . . . . . . . . . . 27

3.2.1 Evaluating Based on Attendance . . . . . . . . . . . . . . . . . 27

3.2.2 Evaluating Students with no Previous Coding Experience . . . . . . . 29

3.3 Evaluating Sense of Belonging . . . . . . . . . . . . . . . . 30

3.3.1 Based on Demographics .................... 31 
3.3 .2 Based on Attendance . . . . . . . . . . . . . . . . . . . . . . . . . 32

4 Conclusions and Future Work . . . . . . . . . . . . . . . . . . . 34

4.1 Primary Results . . . . . . . . . . . . . . . . . . . . . . 34

4.2 Other Results and Observations . . . . . . . . . . . . . . . . . . 34

4.3 Lessons Learned . . . . . . . . . . . . . . . . . . . . . 35

Bibliography . . . . . . . . . . . . . . . . . . 37

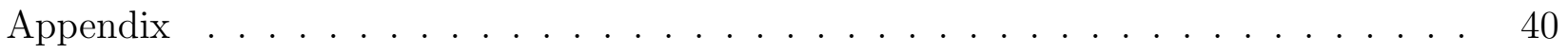

A.1 List of Data Collected . . . . . . . . . . . . . . . . 40

A.2 Attitudinal Surveys . . . . . . . . . . . . . . . . . . . 41

A.3 Curriculum Guide . . . . . . . . . . . . . . . . . . . . . . 48

A.4 Reference Code . . . . . . . . . . . . . . . . . . . . . . . 49

A.4.1 Learning Retention Graphs . . . . . . . . . . . . . . . 49

A.4.2 Sense of Belonging Graphs . . . . . . . . . . . . . . . . 52 


\section{List of Tables}

Table Page

1.1 Active Learning Costs and Benefits . . . . . . . . . . . . . 15

2.1 Study Session Schedule . . . . . . . . . . . . . . . . . . . . . . 22

2.2 CS1 Misconceptions Covered in PI Questions . . . . . . . . . . . . . . . . 24

3.1 Race and Programming Experience of Students who Attended Fourth Hour . 26

3.2 Percentages of Race Populations in CS149 that Attended Fourth Hour . . . . 26

3.3 Sense of Belonging Differences based on Fourth Hour Attendance . . . . . . 32 


\section{List of Figures}

Figure Page

3.1 Fourth Hour Attendance per Session _ . . . . . . . . . . . . . . . 25

3.2 CS149 Content Retention Based on Fourth Hour Attendance . . . . . . . . . 28

3.3 CS149 Students with No Prior Coding Experience; Evaluating Content Retention Based on Fourth Hour Attendance . . . . . . . . . . . . . . 29

3.4 Sense of Belonging in CS149 Students . . . . . . . . . . . . . . . . 31

3.5 Sense of Belonging in CS149 Students based on Fourth Hour Attendance . . 33 


\title{
Abstract
}

\author{
A PILOT STUDY ON THE IMPACT OF TEACHING ASSISTANT LED CS1 STUDY \\ SESSIONS USING PEER INSTRUCTION \\ Megan Gilbert \\ James Madison University, 2020 \\ Thesis Advisor: Dee A. B. Weikle, Ph.D.
}

James Madison University's Computer Science program strives to be a student-centered learning environment with a focus on creating a community for undergraduate success. National data reveals computer science has the lowest student retention rate compared to other STEM majors. The National Center for Women and Information Technology (NCWIT) has compiled a list of ways to retain students in Computer Science. In particular, NCWIT calls for collaboration indicate that "a sense of belonging, or a feeling of fit, is important for supporting student interest and persistence." One aspect of creating community is the department's longstanding commitment to provide undergraduate teaching assistants (TAs). Traditionally, TAs provide one-on-one help in the classroom and also hold supplementary lab hours in the evenings to answer questions. As part of this honors project, we have developed a new program called "The Fourth Hour" to increase student retention. Led by TAs using Peer Instruction (PI), these weekly study sessions provide a structured review of introductory topics.

The aim of this research is to discover if weekly study sessions promote an environment in which students feel an increased sense of belonging and improved course material retention. In the Fall 2019 semester, JMU offered ten sections of CS149, the introductory programming 
course, also known as "CS1" in the literature. Each section had approximately 30 students enrolled. Four TAs were chosen to lead one study session each week using the same lesson materials. Three attitudinal surveys were administered over the duration of the semester to collect data on student demographics, self-efficacy, and sense of belonging. Pre- and postassessment results were recorded to test student course material retention. Study session attendance was also collected to discern if there was a correlation with student demographics, self-efficacy, sense of belonging, and/or course material retention. Anomalies in the data and inconsistent attendance rates limited the statistical significance of our results. However, our qualitative analysis suggests that the study sessions had a positive impact on students. As a result, the CS department is planning to continue offering the Fourth Hour program. 


\section{Chapter 1: Introduction}

\section{$1.1 \quad$ Purpose and Objectives}

\subsubsection{Motivation}

James Madison University strives to create a strong community in which, upon graduation, students feel prepared to "lead productive and meaningful lives" [1]. The University aims to follow six key values: Academic Quality, Community, Diversity, Excellence, Integrity, and Student Focus. By adopting these key values, JMU hopes to create an engaging environment which promotes student success.

Likewise, JMU's Computer Science department seeks to foster an environment that encourages the collective university's student-centered values. The Computer Science department promotes student learning through multiple outlets. All class sizes (with the exception of CS101) are capped at 30 students to create a personal environment. Clubs allow students to form cohorts and support systems. Diversity is promoted through active clubs, such as Women in Technology, where an underrepresented group in Computer Science is given a voice. A STEM career fair is offered to assist students in obtaining internships and employment prior to graduation. In conclusion, JMU's Computer Science program aims to build an environment in which students believe that they are a member of a community in which they can succeed.

Although JMU's program strives to create a community for students to flourish, Computer Science can be a challenging major - especially as several students have no coding experience prior to university. Across the United States, data exhibits that Computer Science has the lowest retention rate among STEM majors [2]. According to the National Science 
Foundation, from 2003-2009 it is estimated that the average retention rate for students in physical/computer/mathematical sciences at 4-year institutions was barely over 40\%. But, overall retention in this category was lower than all other STEM majors. This raises the question: How can we increase retention rates in Computer Science?

To be formally accepted the Computer Science major at JMU, students must obtain a "B" average upon concluding their first two required Computer Science courses. CS149 and CS159 act as the foundation courses required by JMU students seeking to be accepted into the Computer Science Program. Upon completion of these courses, students will have the opportunity to apply to the major. Could more class time in CS1 courses be the answer? Two years ago, JMU offered a 4-credit introductory CS1 course registered as CS139 in the course catalog in addition to the 3-credit equivalent course CS149. The 4-credit course allowed for students to meet one extra hour a week. But research showed that on average the 4-credit course did not reap additional benefits as students received similar grades as students in the 3-credit course. A study conducted by JMU faculty discovered the retention rate, defined as students continuing or graduating from the Computer Science program, was no different for students enrolled in CS139 versus CS149 [3].

As of 2017, CS139 has ceased being offered. It may be important to note that students would self-select into the section of CS1 that they wanted to take (CS139 or CS149) and a variety of factors may have prevented students from enrolling in CS139. For example, the 4-credit course may have been harder to fit into student schedules. Other science courses offered at JMU often offer labs and lectures independent of one another. It can sometimes be more straightforward for students to fit a 3-credit lecture class, and 1-credit lab class into their schedule. In addition, anecdotal evidence indicated that some students with prior experience still selected CS139, removing some of the benefits to those without experience being in a class with others of similar background.

Eliminating major requirements may seem to be a plausible way of increasing student retention, but previous results suggest this approach is unnecessary. Past evidence from a 
study performed by JMU faculty indicates that the grade a student earned in CS1.5 (equivalent to CS159 Object-Oriented Programming) affected student retention in CS2 (equivalent to CS240 Data Structures and Algorithms) courses [3]. This research informed the grade requirements for acceptance to the major as it indicates mastery of the introductory content is essential to student future success in completing the major. Students that fail to meet requirements traditionally must retake courses or do not complete the major [3]. Major requirements were therefore put in place with the intention of benefiting students. These major requirements were first enacted the Fall Semester of 2016. Research on the effects of this change has yet to be done and data is only now becoming available as the first applicants under these new constraints are just graduating this academic year.

JMU's Computer Science program supports a Teaching Assistant (TA) program to aid students in CS0 (equivalent to CS101 survey course for non-majors), CS1 (equivalent to CS149 and CS159 Programming Fundamentals), and CS2 (equivalent to CS240 Data Structures and Algorithms) courses. CS1 professors often have a TA supporting them during class hours. TAs are also available to assist students in evening lab hours that are offered Monday-Thursday 5PM to 11PM and Sundays from 1PM to 11PM. During Spring 2019 when this project was proposed, out of the twenty-five TAs there were eight TAs acting as Lead TAs. In general, Lead TAs have the same responsibilities as regular TAs with some additional tasks including: reporting concerns to faculty, supervising of other TAs during a shift, collecting data for the shift, and brainstorming ideas to enhance the current TA program. Lead TAs are also responsible for reporting the most commonly asked questions succeeding their lead shift. Students predominantly arrive with questions regarding their programming assignments (versus conceptual questions). During Fall 2018 and Spring 2019 lead TAs, to aid in student understanding of course concepts, introduced a weekly review session program. Weekly review sessions cover concepts taught the previous week during lecture. The aim was to assist CS1 students in retaining and comprehending course concepts, so they perform well on assessments. Review sessions at this time created by Lead TAs were 
unstructured - they did not utilize any learning pedagogy's facilitation guidelines. Despite this, students appeared to enjoy session availability, especially prior to exams.

Supplemental resources such as access to TA assistance can be helpful to students seeking extra assistance. But, it is also vital that students feel comfortable in seeking assistance when they are struggling to grasp learning material. Sense of belonging often aids in fostering student success [4]. The National Center for Women and Information Technology's (NCWIT) efforts stress the importance of student attitudes. Belonging becomes important especially for the success in underrepresented groups. The idea of belonging or "fit" can encourage student persistence [4]. Persistence is often vital in work heavy courses. Collaborative learning can form a sense of belonging among student groups. NCWIT recommends Peer Lead Team Learning (PLTL) as a collaborative setting in which peers aid student learning in workshops outside of traditional class hours [5]. Studies suggest, specifically in chemistry courses that PLTL can improve student attitudes. Students in a particular study report that they feel PLTL positively impacted their learning experience [6]. Positive feeling paired with collaboration can foster a sense of belonging. Creating an environment where students recognize they belong can be vital in student persistence within STEM majors.

\subsubsection{Goals/Overview}

The purpose of this study was to test the question if a structured study session led by Teaching Assistants (TAs) and attended regularly could increase CS1 material retention and attitudes in the Computer Science Program at JMU. To test this question, a structured CS1 study session curriculum was designed and implemented during Fall Semester 2019 to observe if a Lead TA (peer-run) study session program would be a beneficial addition to the JMU Computer Science Program. Four Lead TAs were chosen by the TA supervisor. Each of these TAs led one study session each week using the same lesson materials. Learning materials

such as worksheets and slides in every study session were identical. Students completed a pre- and post-semester assessment that covered all of the material that was reviewed during 
the study sessions for the duration of the whole semester. All students registered in CS149 were invited to participate in the study. Students absent from all study sessions were used as a control group.

Students that consented to participating in the study were asked to complete the presemester assessment during the first week of their CS149 class. A week before finals, those same students were asked to take the post-semester assessment. Results from pre- and post-semester assessments serve as the measure of CS1 material retention. CS1 student attitudes were measured three times over the course of the semester during week 2 , week 8 , and week 14. Attitudes were calculated using student survey responses. Attitudes and CS1 material retention were compared upon completion of the study to analyze the effectiveness of the introduction of a structured study session program.

\subsection{Background: Choosing a Teaching Pedagogy}

Several teaching pedagogical approaches were under consideration for this project. It was determined study sessions would be designed to follow the teaching methodology of Peer Instruction but Peer Led Team Learning, Process Oriented Guided Inquiry Learning, and Pair Programming were also investigated. Note that only active learning methodologies were considered because there is strong empirical evidence that active learning produces better learning outcomes [7]. An outline of costs and benefits is described in Table 1.1.

\subsubsection{Peer Led Team Learning}

Peer Led Team Learning (PLTL) breaks students into groups of up to eight students. Groups are led by a peer leader or TA. Worksheets are given to teams to complete over a given workshop period [8]. PLTL benefits include "significant gains in performance, retention,

perseverance, and student attitudes and opinions" in STEM areas [9]. The resources PLTL requires are significant: one TA per group of eight students, one classroom per group, and 
at least two hours of workshop time each week. Due to lack of resources, PLTL was out of scope for this experiment. Instead, PLTL materials and attitude assessments will act as references and a comparison tool for this study. Peer Instruction was instead chosen for this study for its ability to allow students to work collaboratively in small groups like PLTL but without the need for an extensive amount of resources. As described below, there is evidence that PI also increases student performance and retention.

\begin{tabular}{|c|c|c|}
\hline & Pros & Cons \\
\hline $\begin{array}{l}\text { Peer Led } \\
\text { Team Learning }\end{array}$ & $\begin{array}{l}\text { - Small groups } \\
\text { - Increase performance } \\
\text { - Increase student retention } \\
\text { - Promotes collaboration } \\
\text { - Increase attitudes } \\
\text { - Interaction with students farther in } \\
\text { the curriculum }\end{array}$ & $\begin{array}{l}\text { - Groups must be chosen well } \\
\text { - Group attendance is imperative } \\
\text { - Resource intensive } \\
\text { - } 1 \text { classroom per group } \\
\text { - } 1 \text { peer-leader per group } \\
\text { - Must meet 2-hours each week }\end{array}$ \\
\hline $\begin{array}{l}\text { Process Oriented } \\
\text { Guided Inquiry } \\
\text { Learning }\end{array}$ & $\begin{array}{l}\text { - Small groups } \\
\text { - Increase performance } \\
\text { - Increase student retention } \\
\text { - Promotes collaboration } \\
\text { - Increase attitudes } \\
\text { - Student roles are well outlined } \\
\text { - Promote learning in new contexts }\end{array}$ & $\begin{array}{l}\text { - Groups must be chosen well } \\
\text { - Group attendance is imperative } \\
\text { - Resource intensive (worksheets) } \\
\text { - Requires training to promote } \\
\text { successful implementation } \\
\text { - Activities must follow guidelines }\end{array}$ \\
\hline $\begin{array}{l}\text { Pair } \\
\text { Programming }\end{array}$ & $\begin{array}{l}\text { - Small groups } \\
\text { - Increase performance } \\
\text { - Increase student retention } \\
\text { - Promotes collaborative programming } \\
\text { - Simulates real-world software } \\
\text { development environments, tools }\end{array}$ & $\begin{array}{l}\text { - Groups must be chosen well } \\
\text { - Groups attendance is imperative } \\
\text { - Projects must be group projects } \\
\text { - Technology must be accessible }\end{array}$ \\
\hline $\begin{array}{l}\text { Peer } \\
\text { Instruction }\end{array}$ & $\begin{array}{l}\text { - Small groups } \\
\text { - Increase performance } \\
\text { - Increase student retention } \\
\text { - Promotes collaboration } \\
\text { - First-time professors generally make } \\
\text { good PI questions } \\
\text { - Increase in student retention is } \\
\text { immediate } \\
\text { - Allows for flexibility } \\
\text { - Groups can change each class period }\end{array}$ & $\begin{array}{l}\text { - Technology must be accessible } \\
\text { - Groups must feel encouraged to } \\
\text { discuss "why" they chose answer } \\
\text { - PI questions must be well designed }\end{array}$ \\
\hline
\end{tabular}

Table 1.1: Active Learning Costs and Benefits 


\subsubsection{Process Oriented Guided Inquiry Learning}

Process Oriented Guided Inquiry Learning (POGIL) requires students form groups of approximately four students. Each student is designated with a specific role. Roles often rotate each class period. Each class, students are given a packet to complete as a team. Professors observe, guide, and aid students that have any questions. POGIL was considered for this experiment due to its popularity within JMU's Computer Science Department. Several professors use POGIL instead of lecture. Team learning can reduce the feelings of isolation and competitiveness which is essential for retaining non-traditional students [10]. Although POGIL has positive material retention results, often professors teaching the course have to go through training before starting [9]. Perfecting the style of teaching using POGIL requires experience. POGIL also encourages groups to contain the same students throughout the semester. POGIL was unrealistic for this experiment as study session attendance varies from week to week and students were not required to attend, whereas in a traditional POGIL setting attendance is required. POGIL is practiced and designed more for a traditional classroom setting versus a study session program.

\subsubsection{Pair Programming}

Pair Programming was another consideration for this project. This style of learning allows two students to pair up and collaborate on a coding assignment. One student is allowed to code at a time while the other observes. Students acting as the observer often discover coding mistakes early. The observer is also tasked to provide insights in forming solutions [11]. PairProgramming has shown positive overall results in increasing retention and performance, for example in studies at the University of California at Santa Cruz (UCSC) [12]. JMU currently has TAs that help with coding concepts in the evenings. In addition, the study sessions focus on CS1 concepts as opposed to coding. 


\subsubsection{Peer Instruction}

Peer Instruction (PI) was chosen as the basic guideline for the study sessions as data shows that even for first-time professors, the results of using PI are still significant in helping students retain material [13]. Unlike a regular lecture, PI tries to increase student retention of material by having students work together to answer questions. First, students will be asked to answer a question individually via an online quiz tool. Then, students will break off into groups to discuss their answers and collectively come up with a group answer. When students form groups after initially answering the question themselves, overall responses increase in accuracy [14]. Afterwards, students are asked to work individually to answer another question that is similar in content to the first. Findings show that individual scores increase for the second question [14]. Because of the positive data that PI reflects and the fact that first-time professors are able to perform well using PI (students are able to successfully benefit and retain information from professors who use PI for the first time), PI was chosen as the methodology used for the study sessions.

\subsection{Related Work}

Prior work in the field that inspired this project includes research on Peer Led Team Learning, papers on Peer Instruction, and the unstructured study session program developed by lead TAs at James Madison University during Fall 2018 and Spring 2019.

PLTL (Peer-Led Team Learning) was recommended because of the success in the research literature. Rydr and Hari show a way in which the program can be used to help students who have little to no programming experience or are in minority groups [15]. The class was offered as an additional one credit optional course. The class is "supplemental learning, not remedial". The inital plan had been to design the study session program as a Pass/Fail one credit "did you show up" course. Due to lack of resources and shortage of time, implementing PLTL as a one credit course became infeasible. But, it continually inspired the idea of the 
study session program as a form of increasing inclusively in minority groups and providing aide for students struggling in CS1 courses.

PI (Peer Instruction) was considered early on as a possible teaching pedagogy. An instructor who uses Peer Instruction in several of their courses recommended several PI resources. A journal entry written by Zingaro and Porter aims to answer the question if instructor intervention after students answer questions in a PI classroom environment is beneficial [13]. According to this study, the answer is yes. Every student no matter how good of a student they are not only benefits from a PI environment, but succeeds even more when an instructor intervenes (discussion after answers are given). This paper was used to model implementation of PI questions for this study.

Taylor et. al. aim to answer the question if professors are correctly using PI, and when do they become proficient at coming up with PI questions [14]. According to the study, professors using PI come up with decent questions in the first year of using PI in their class. But, within 2 years, their questions become $2 \mathrm{x}$ better. This article shows it is doable for a first time instructor to be able to come up with good questions. This article aided in choosing PI as the teaching pedagogy for the study session program as it showed promise TAs would be able to implement PI effectively within the first year.

Dillon and Slattery [16] describe a curriculum revision at Michigan State University. Attempting to increase CS retention, confidence, and sense of belonging in an MSU CS1 course, a support class was created as part of larger "efforts to broaden diversity." The support class nicknamed Computational Thinking Lab (CTL) was designed as a 1 credit supplementary course for students enrolled in the CS1 course at MSU. The CS1 course at MSU is a 4-credit course with 120 student lectures and 25 student labs. Students in CTL met once a week for 2-hours. CTL sessions were led by undergraduate peer leaders following PLTL teaching pedagogy [17]. Results showed students enrolled in CTL experienced an increase in sense of belonging over the course of the semester, had higher grades on average than the non-CTL group, and "none of the CTL students dropped or withdrew" [16]. The 
experiment performed at MSU published in 2018 depicts the type of program this study originally considered. Due to lack of resources a 1-credit course and PLTL were infeasible. But, a similar program was created using PI given the resources at JMU. It is important to note that JMU CS1 equivalent courses are relatively small compared to MSU with a max of 30 students in each CS1 section at JMU. 


\section{Chapter 2: Implementation}

\subsection{Study Session Design}

\subsubsection{Session Overview}

Sessions were designed to review CS1 concepts taught the previous week. For example, if students learned about Concept A on Week 1, the study session on Week 2 would review Concept A. Study sessions were offered three times a week: Monday 6-7pm, Tuesday 6-7pm, and Wednesday 6-7pm.

Four TAs were hired to lead the study sessions. Three TAs acted as primary study session TAs while one TA acted as a secondary study session TA. Primary TAs would typically act as presenter and observer both once a week. The secondary study session TA was asked to act as a presenter or observer when one of the primary TAs was unavailable due to illness or schedule conflict. Two TAs were always present during the study sessions. One TA acted as the presenter and the other the observer. The presenter's responsibilities included leading the session by reviewing slides with students, answering student questions, and working out CS1 problems. The observer was responsible for collecting study session attendance, ensuring all CS1 concepts were described correctly by the presenter, and answering questions the presenter was unsure or unable to answer.

Slideshows, activities, and worksheets created by a Lead TA were reviewed by a faculty supervisor prior to being presented to CS1 students during the Fourth Hour study sessions. Slideshows were shared amongst study session TAs through Google Drive ensuring all three study sessions offered each week contained identical supplementary learning materials. A typical study session would begin with asking students to introduce themselves as many 
students came from various sections of CS1. Each week a slideshow was used to guide the study session lesson plan. Slideshows included three Peer Instruction Questions, cooperative CS1 activities and problems for groups of 2-3 students to solve, and typically reviewed chapter vocabulary. Sessions encouraged students to work together to solve various problems. Music was often played to encourage a friendly relaxed environment.

\subsubsection{Session Schedule}

The Fourth Hour schedule can be found in tabular form on the following page. All materials used during study sessions are publicly available via https://github.com/mGilbert15/ The-Fourth-Hour. Note that study sessions were not offered the week of Thanksgiving Break as James Madison University Campus and Residential Halls were closed. The first week of the semester served as a crucial time for advertising the Fourth Hour. Flyers, and emails were sent to students registered in CS149 during Week 1 of the semester advertising the Fourth Hour.

\subsubsection{Implementing Peer Instruction}

When implementing Peer Instruction (PI), we chose the free online tool Socrative. Within the Computer Science Department at JMU, several professors have utilized Socrative in the classroom. Socrative has been used as a tool when implementing PI and gaining student interaction in class. Wash [18] found that students reported strong agreement that using an online tool such as Socrative increased their class participation, helped them receive feedback on their performance, and aided in creating positive interactions with their peers and/or professor. Socrative is easily accessibly as it is free to students, a classroom code is used to sign in as opposed to creating a personal account, and platform friendly: usable on mobile devices and laptops [19].

At the beginning of the semester a Socrative classroom was created for the Fourth Hour. Prior to the first PI question, students were requested to access the Socrative classroom using 


\begin{tabular}{|c|l|}
\hline Week of Semester & Review Session and Topic \\
\hline Week 1 & No session. Focus on advertising Fourth Hour. \\
\hline Week 2 & Session 1 - Printing and Print Formatting \\
\hline Week 3 & Session 2 - Variables and Operators \\
\hline Week 4 & Session 3 - Input and Output \\
\hline $\begin{array}{c}\text { Week } 5 \\
\text { Week of Midterm } 1\end{array}$ & Session 4 - Methods and Midterm Review \\
\hline Week 6 & Session 5 - Testing Code \\
\hline Week 7 & Session 6 - Boolean Logic \\
\hline Week 8 & Session 7 - Loops and Strings \\
\hline Week 9 & Session 8 - Arrays \\
\hline $\begin{array}{c}\text { Week } 10 \\
\text { Week of Midterm } 2\end{array}$ & Session 9 - Recursion and Midterm Review \\
\hline Week 11 & Session $10-$ Nested For-Loops \\
\hline Week 12 & Session $11-$ Intro to Objects \\
\hline Week 13 & Session $12-$ UML \\
\hline $\begin{array}{c}\text { Week } 14 \\
\text { Thanksgiving Break }\end{array}$ & No Session Offered \\
\hline $\begin{array}{c}\text { Week } 15 \\
\text { Before Final Exam }\end{array}$ & Session $13-$ Final Exam Review \\
\hline
\end{tabular}

Table 2.1: Study Session Schedule

the classroom code and URL displayed on the weekly slideshow. TAs running sessions set up the PI quiz allowing students to use software anonymously and questions were teacher-paced allowing TAs to allow 1-2 minutes per-question based on student interactions. The first time a question appeared, students were asked to complete the multiple choice or true-false question independently. After 1-2 minutes, the TA would move on to the next question (which was identical to the first question) but students were now allowed to talk in groups of 2-3 students to discuss their answers. Students were encouraged by the presenting TA to share why they chose a particular answer during the first round of questioning within their groups. Students were permitted to change their answer during the question-repeat. After students finished answering the question-repeat TAs shared the percentages of students who chose each particular answer. Using the whiteboard or slideshow the presenting TA would go 
over both the correct answer and why the other answers were incorrect. Over the course of the study session, two more PI questions would be administered using the identical process described above.

\subsubsection{Creating Peer Instruction Questions}

Our Peer Instruction lessons consisted of multiple choice and true/false questions about topics JMU Computer Science faculty recognized students often miss on assessments. The questions were specifically designed to address these misconceptions. Kaczmarczyk et al. discovered four main themes in CS1 student misconceptions [20]:

- T1: Students misunderstand the relationship between language elements and underlying memory usage.

- T2: Students misunderstand the process of while loop operation.

- T3: Students lack a basic understanding of the Object concept.

- T4: Students cannot trace code linearly.

These themes guided our selection of topics for the Peer Instruction lessons. The authors developed a further breakdown of T1 (regarding memory usage):

- MMR1: Semantics to semantics

- MMR2: All Objects same size

- MMR3: Instantiated no memory allocation

- MMR4: Uninstantiated memory allocation

- MMR5: Off by 1 array construction

- PVR1: Primitive no default

- PVR2: Primitives don't have memory

Most of these misconceptions are self-explanatory to Computer Science faculty, with a couple exceptions. We will refer to "semantics to semantics", which refers to a student misunderstanding variable declaration by applying real world semantics to the process, as 
"semantics to variable declarations". And we will refer to "primitive no default", which refers to a student misunderstanding that instance variables of a class have no default value, as "instance variable no default". Table 2.2 describes the misconceptions covered each week (session) of the Fourth Hour. (The themes T1-T4 have been paraphrased to save space.)

\begin{tabular}{|l|c|c|c|c|c|c|c|c|c|c|c|c|c|}
\hline & $\mathrm{S} 1$ & $\mathrm{~S} 2$ & $\mathrm{~S} 3$ & $\mathrm{~S} 4$ & $\mathrm{~S} 5$ & $\mathrm{~S} 6$ & $\mathrm{~S} 7$ & $\mathrm{~S} 8$ & $\mathrm{~S} 9$ & $\mathrm{~S} 10$ & $\mathrm{~S} 11$ & $\mathrm{~S} 12$ & $\mathrm{~S} 13$ \\
\hline $\begin{array}{l}\text { Language elements \& } \\
\text { memory usage }\end{array}$ & $\mathrm{X}$ & $\mathrm{X}$ & $\mathrm{X}$ & $\mathrm{X}$ & & $\mathrm{X}$ & $\mathrm{X}$ & $\mathrm{X}$ & $\mathrm{X}$ & $\mathrm{X}$ & $\mathrm{X}$ & & $\mathrm{X}$ \\
\hline While loop operation & & & & & & & & & & & & $\mathrm{X}$ & \\
\hline The Object concept & & & $\mathrm{X}$ & & & & $\mathrm{X}$ & $\mathrm{X}$ & $\mathrm{X}$ & $\mathrm{X}$ & $\mathrm{X}$ & & $\mathrm{X}$ \\
\hline Cannot trace code linearly & & & & $\mathrm{X}$ & & $\mathrm{X}$ & $\mathrm{X}$ & $\mathrm{X}$ & $\mathrm{X}$ & $\mathrm{X}$ & $\mathrm{X}$ & & $\mathrm{X}$ \\
\hline $\begin{array}{l}\text { Semantics to variable } \\
\text { declarations }\end{array}$ & & $\mathrm{X}$ & & $\mathrm{X}$ & $\mathrm{X}$ & & $\mathrm{X}$ & $\mathrm{X}$ & $\mathrm{X}$ & $\mathrm{X}$ & $\mathrm{X}$ & $\mathrm{X}$ & $\mathrm{X}$ \\
\hline All objects same size & & & & & & & & $\mathrm{X}$ & $\mathrm{X}$ & $\mathrm{X}$ & $\mathrm{X}$ & & $\mathrm{X}$ \\
\hline $\begin{array}{l}\text { Instantiated no memory } \\
\text { allocation }\end{array}$ & & & $\mathrm{X}$ & & & & $\mathrm{X}$ & $\mathrm{X}$ & $\mathrm{X}$ & $\mathrm{X}$ & $\mathrm{X}$ & & $\mathrm{X}$ \\
\hline $\begin{array}{l}\text { Uninstantiated memory } \\
\text { allocation }\end{array}$ & & & & & & & $\mathrm{X}$ & & & & & & \\
\hline Off by 1 array construction & & & & & & & & $\mathrm{X}$ & $\mathrm{X}$ & $\mathrm{X}$ & & & $\mathrm{X}$ \\
\hline Instance variable no default & & & $\mathrm{X}$ & & & & & & & & & & \\
\hline Primitives don't have memory & $\mathrm{X}$ & & $\mathrm{X}$ & $\mathrm{X}$ & & $\mathrm{X}$ & $\mathrm{X}$ & $\mathrm{X}$ & $\mathrm{X}$ & $\mathrm{X}$ & $\mathrm{X}$ & & $\mathrm{X}$ \\
\hline
\end{tabular}

Table 2.2: CS1 Misconceptions Covered in PI Questions 


\section{Chapter 3: Results}

\subsection{Participant Attendance and Demographics}

\subsubsection{Attendance}

282 students registered for CS149 Fall 2019, of which 262 students participated in the study. 71 unique students attended the Study Session program at least once. 69 out of the 71 students that attended Fourth Hour gave consent to participate in the study. Study Session attendance was collected every week and analyzed at the end of the semester. Results shown in Figure 3.1 depict a trend of increased attendance on midterm/exam weeks. Weeks following exams show a large decrease in student attendance. For the purpose of this study, No Frequency refers to students who never attended Fourth Hour (0 times), Low Frequency (1-3 times), and High Frequency (4+ times). 193 students fall into No Frequency category, 59 in Low Frequency, and 11 in High Frequency.

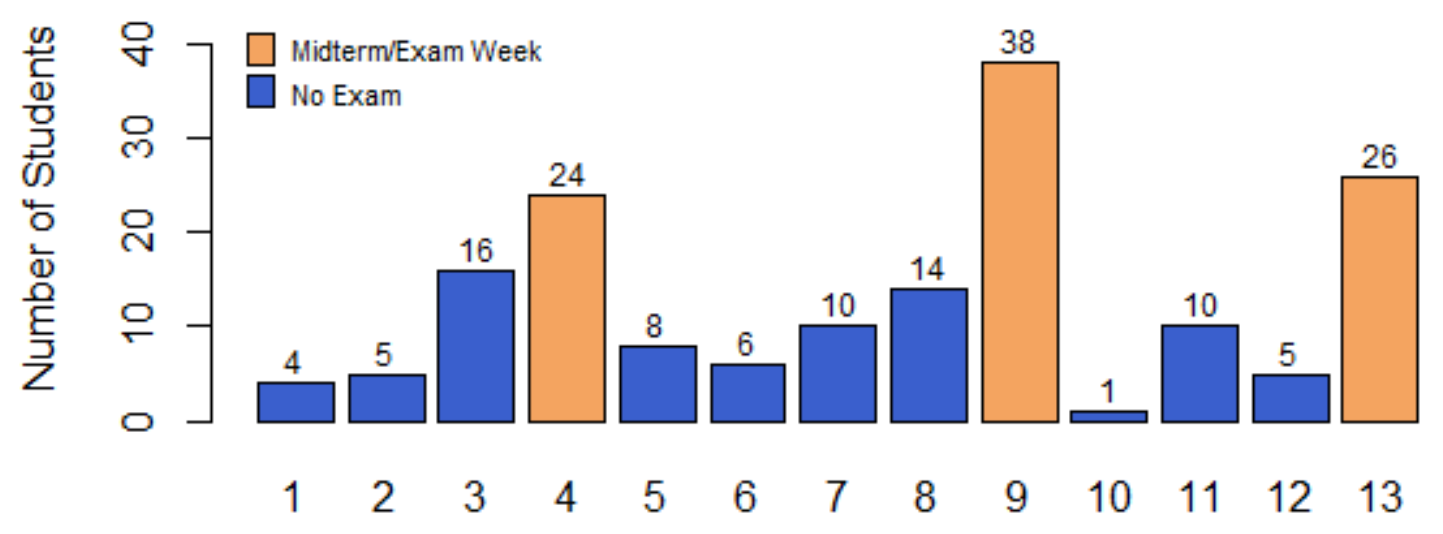

Figure 3.1: Fourth Hour Attendance per Session 


\subsubsection{Demographics}

Demographic data was collected from students in Survey 1, which included student race, gender and prior programming experience, among other information.

\begin{tabular}{|c|c|c|c|c|c|}
\hline Race & $\begin{array}{c}\text { Total Number } \\
\text { of Students }\end{array}$ & $\begin{array}{c}\text { No } \\
\text { Programming } \\
\text { Experience }\end{array}$ & $\begin{array}{c}\text { Percentage No } \\
\text { Programing } \\
\text { Experience }\end{array}$ & $\begin{array}{c}\text { Previous } \\
\text { Programming } \\
\text { Experience }\end{array}$ & $\begin{array}{c}\text { Percentage with } \\
\text { Programming } \\
\text { Experience }\end{array}$ \\
\hline Asian & 5 & 4 & $80 \%$ & 0 & $0 \%$ \\
\hline $\begin{array}{c}\text { Black or } \\
\text { African } \\
\text { American }\end{array}$ & 7 & 5 & $71 \%$ & 2 & $29 \%$ \\
\hline $\begin{array}{c}\text { Hispanic or } \\
\text { Latina/Latino }\end{array}$ & 6 & 4 & $67 \%$ & 2 & $34 \%$ \\
\hline Other & 1 & 0 & $0 \%$ & 1 & $100 \%$ \\
\hline White & 50 & 21 & $42 \%$ & 29 & $58 \%$ \\
\hline
\end{tabular}

Table 3.1: Race and Programming Experience of Students who Attended Fourth Hour

\begin{tabular}{|c|c|c|}
\hline Race & $\begin{array}{c}\text { Number of Students who } \\
\text { Attended Fourth Hour }\end{array}$ & $\begin{array}{c}\text { Total Percentage of Race } \\
\text { Population Across CS149 }\end{array}$ \\
\hline Asian & 5 & $19 \%$ \\
\hline Black or African American & 7 & $47 \%$ \\
\hline Hispanic or Latina/Latino & 6 & $43 \%$ \\
\hline Other & 1 & $20 \%$ \\
\hline White & 50 & $25 \%$ \\
\hline
\end{tabular}

Table 3.2: Percentages of Race Populations in CS149 that Attended Fourth Hour

Among students in the minority bracket who attended Fourth Hour, they were more likely to have no prior programming experience. As shown in Table 3.1, minority groups that attended Fourth Hour consisted of majority minority students with no previous programming experience. Note that several students answered N/A for previous experience in 
the demographics survey. This explains why percentages may not add to $100 \%$. Table 3.2 depicts that almost half of the Black or African American CS149 population and Hispanic or Latina/Latino CS149 population attended the Fourth Hour at least once.

\subsection{Evaluating Content Retention}

To evaluate student content retention over the course of a semester the core assessment scores were analyzed. Calculated CS1 student pre-CA (core assessment) score (out of 100) as well as CS1 student post-CA (core assessment) score (out of 100). Normalized learning gain was calculated to evaluate how much additional information students learned over the course of the semester using the following equation:

$$
(\text { post }- \text { pre }) /(100-\text { pre })
$$

Students with a low normalized learning gain score had less learning gain than students with higher scores. Several students had a negative learning gain score, indicating that they scored higher on the pre-CA than the post-CA. Negative scores could be attributed to good guessing on the pre-CA. A statistical online resource for $\mathrm{R}$ was referenced as a guide for testing significant difference on non-normal data [21] as well as normal data [22].

\subsubsection{Evaluating Based on Attendance}

This section discusses the question: Is there a significant difference in learning retention between students that attended Fourth Hour and students who did not attend Fourth Hour?

To answer this question normalized learning gain scores were compared based on if a student attended Fourth Hour at least once versus never. Figure 3.2 is a visual representation of evaluating learning gain based on Fourth Hour Attendance. Data for students that lacked completion of either the pre-CA or post-CA was omitted in the analysis. 

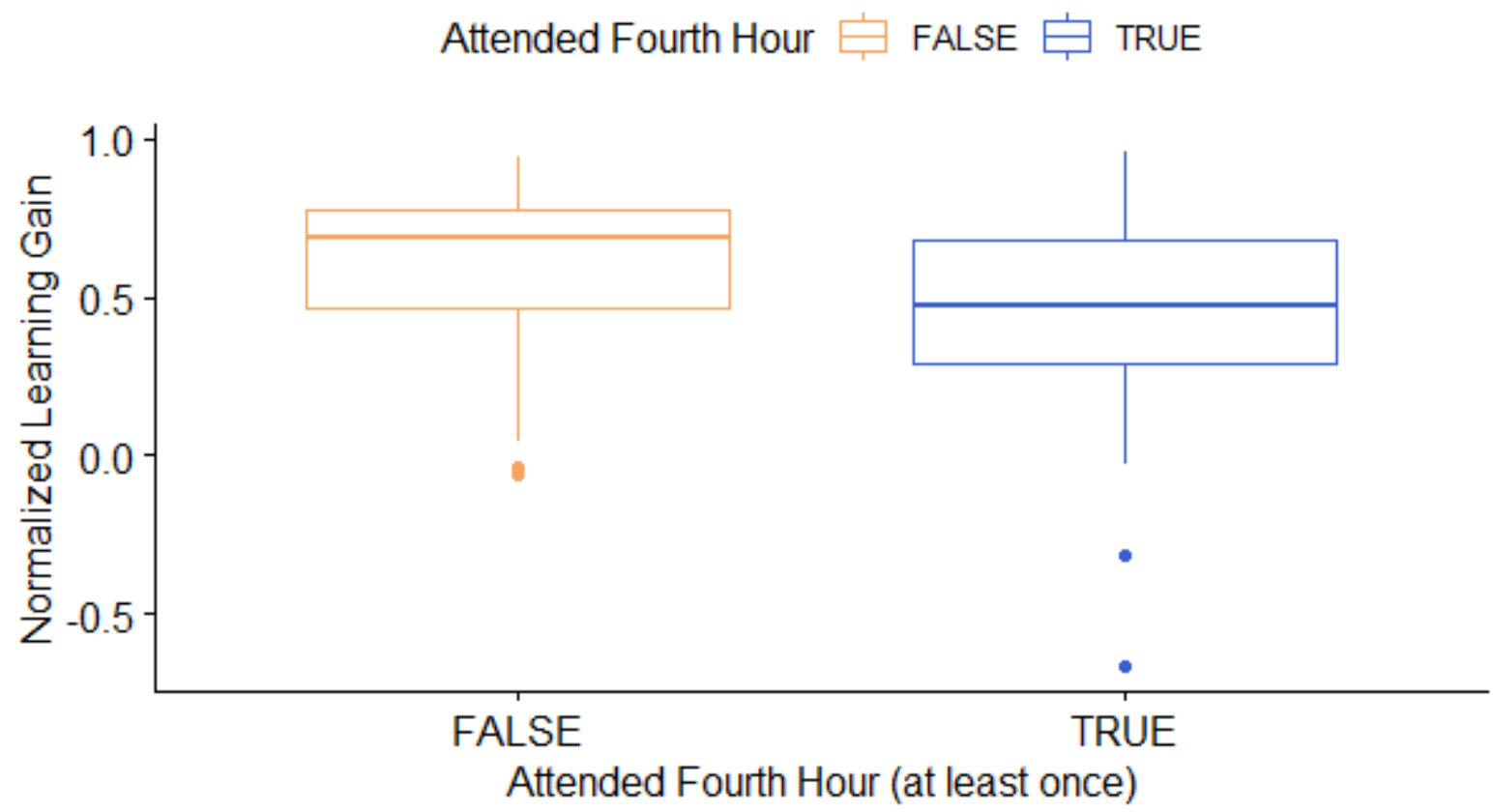

Figure 3.2: CS149 Content Retention Based on Fourth Hour Attendance

To test for significant difference, first the data was evaluated in the programming language R using a Shapiro-Wilk test to evaluate normality with a significance-level of 0.05. Neither the Never-Attended category $(\mathrm{p}=1.474 \mathrm{e}-06)$ nor the Attended category $(\mathrm{p}=0.007993)$ exceeded the significance level $\mathrm{p} i, 0.05$, so the data was not considered normal. Due to this lack of normality, we used a Wilcoxon Rank Sum test to determine that the difference was statistically significant $(\mathrm{W}=2761, \mathrm{p}=0.0004443)$.

This result suggests that there is statically significant difference in learning gain in students who attended the Fourth Hour versus students who never attended the Fourth Hour. Students who did not attend Fourth Hour had higher material retention than students who did attend the Fourth Hour. One plausible explanation is that students who attended the Fourth Hour were more likely to be struggling students seeking help. 


\subsubsection{Evaluating Students with no Previous Coding Experience}

This section discusses the question: Is there a significant difference in learning retention between students who had no previous coding experience who attended Fourth Hour that had High frequency attendance vs. Low frequency attendance?

Similar to the previous question, normalized learning gain scores were compared based on attendance frequency. Data for students that lacked completion of either the pre-CA or post-CA or had indicated prior programming experience were not included in this analysis. The data was determined normal with the High Frequency group receiving a $\mathrm{p}=0.8981$ and Low Frequency receiving $\mathrm{p}=0.206$ based on a Shapiro-Wilk test with a significance level of 0.05. An unpaired 2-tailed T-Test (0.05 significance-level) yielded no statistically significant difference between the two groups $(\mathrm{p}=0.2907)$.

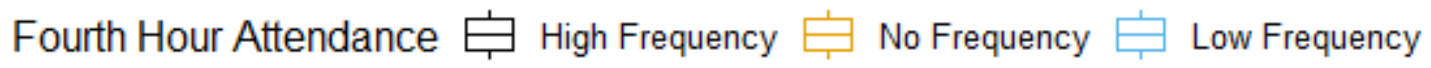

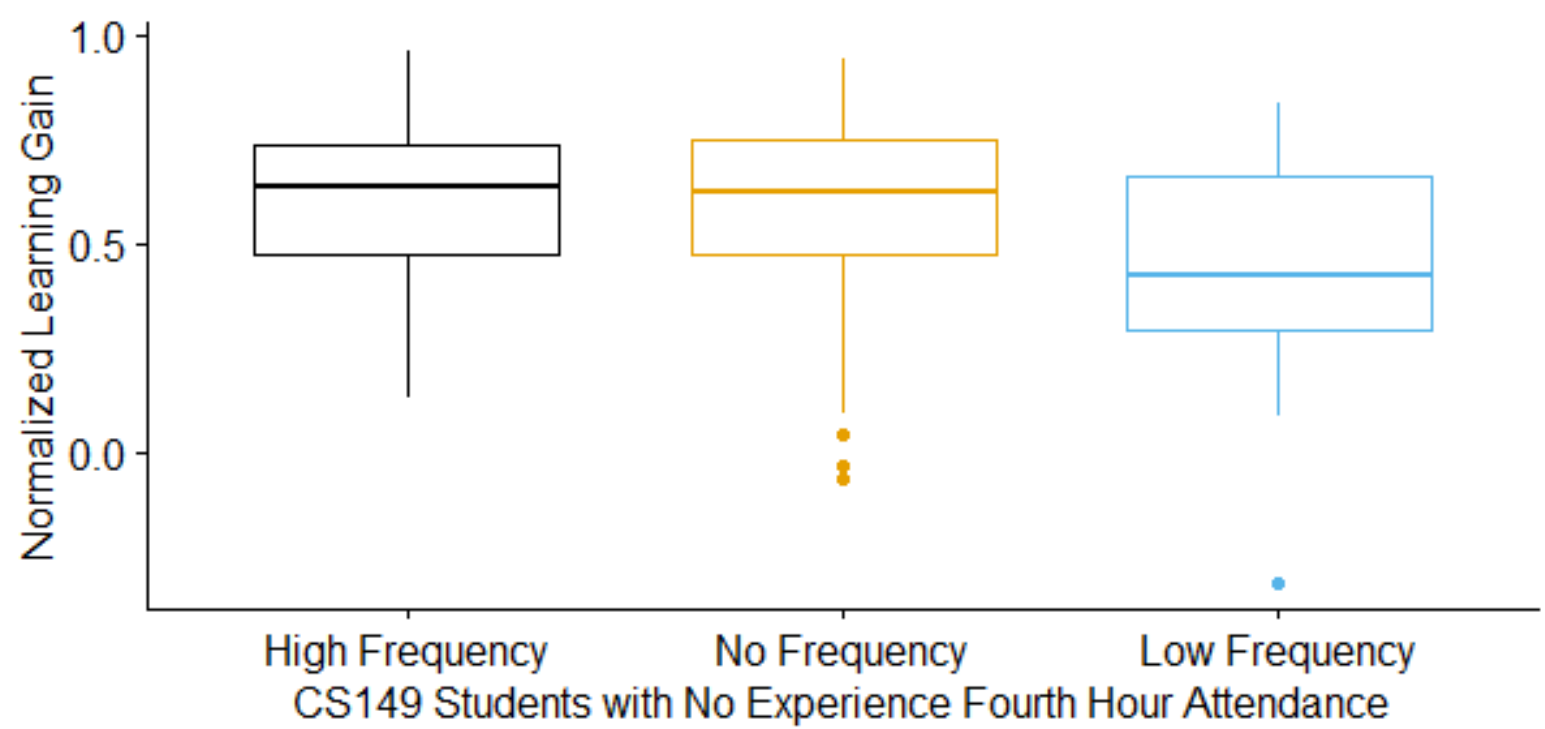

Figure 3.3: CS149 Students with No Prior Coding Experience; Evaluating Content Retention Based on Fourth Hour Attendance

The results from the T-test determined that there was not enough evidence to suggest that there was difference in content retention between students with High and Low Frequency Fourth Hour attendance. Although the mean values appear to differ greatly in Figure 3.3 
(High Frequency 0.592, Low Frequency 0.449, No Frequency 0.568), the sample size was insufficient to suggest the difference was statistically significant (Low Frequency $\mathrm{n}=20$, High Frequency $n=6$ ).

\subsection{Evaluating Sense of Belonging}

Students who participated in the study were asked to take three surveys over the course of the semester. These surveys were not identical, but five questions appeared on all three surveys. These questions were preceded by the statement, "In this computer science class...":

1. I feel that I belong to the computer science community.

2. I feel accepted.

3. I feel like an outsider.

4. I try to say as little as possible.

5. I trust my instructors to be committed to helping me learn.

The purpose of these questions was to track student sense of belonging throughout the semester. But, several students did not complete all three surveys. As a result, analyzing individual sense of belonging change throughout the semester became difficult. In the end, it was decided the last survey would be used to evaluate student sense of belonging at the end of the semester. 204 students completed the third and final attitudinal survey administered on the 14 th week of the semester.

Questions were presented in Likert Scale format. To analyze sense of belonging, each item was given a numerical value. Positive items $(1,2,5)$ were given the numerical values:

- strongly disagree : 1

- disagree : 2

- neutral : 3

- agree : 4

- strongly agree : 5 
Negative items $(3,4)$ numerical value scales were reversed (i.e., strongly disagree : 5, strongly agree : 1). For each student, sense of belong was determined by calculating the mean score among the five items:

$$
(Q 1+Q 2+Q 3+Q 4+Q 5) / 5
$$

Sense of Belonging scores closer to 1.0 will correspond to low student sense of belonging, while scores closer to 5.0 will correspond with high sense of belonging.

\subsubsection{Based on Demographics}

This section discusses the question: Are there differences in responses to the attitude survey based on demographics?

Based on mean scores, there appears to be a difference in sense of belonging based on racial demographics. Due to low sample numbers in each race category, statistical testing was difficult. Mean scores were compared to understand student sense of belonging based on race. A box plot rendered in $\mathrm{R}$ Figure 3.4 depicts sense of belonging in students at the end of semester in CS149 students based on racial demographics. There appears to be a difference in sense of belonging based on racial demographics.

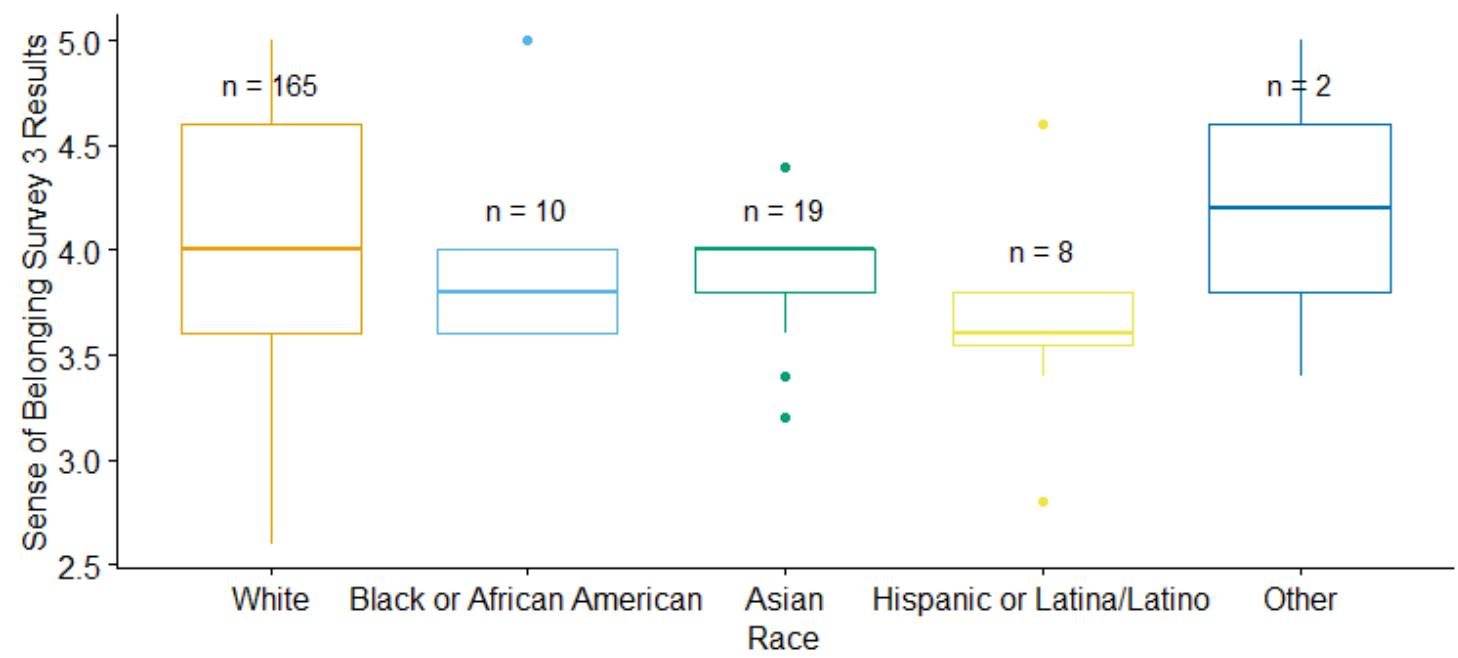

Figure 3.4: Sense of Belonging in CS149 Students 
Table 3.3 depicts sense of belonging in students who attended Fourth Hour vs those that never attended. The last column of the table depicts the difference in sense of belonging of students that attended Fourth Hour vs those that never attended. This calculation was done by subtracting the mean score of students in that racial category that attended Fourth Hour by the mean score of students in that racial category that never attended Fourth Hour. Positive values in the last column indicate students that attended Fourth Hour had a higher sense of belonging than those that never attended while negative values indicate the opposite.

\begin{tabular}{|c|c|c|c|c|c|}
\hline Race & $\begin{array}{c}\text { Never } \\
\text { Attended } \\
\text { Fourth Hour }\end{array}$ & $\begin{array}{c}\text { Sense of } \\
\text { Belonging } \\
\text { Score (Survey } \\
\text { 3) }\end{array}$ & $\begin{array}{l}\text { Attended } \\
\text { Fourth Hour } \\
\text { (at least once) }\end{array}$ & $\begin{array}{c}\text { Sense of } \\
\text { Belonging } \\
\text { Score (Survey } \\
\text { 3) }\end{array}$ & $\begin{array}{l}\text { Fourth Hour } \\
\text { Attendee } \\
\text { scores vs. non } \\
\text { attendees } \\
\text { based on racial } \\
\text { groups }\end{array}$ \\
\hline Asian & 14 & 3.93 & 5 & 3.96 & +0.03 \\
\hline $\begin{array}{l}\text { Black or } \\
\text { African } \\
\text { American }\end{array}$ & 4 & 4.05 & 6 & 3.8 & -0.25 \\
\hline $\begin{array}{c}\text { Hispanic or } \\
\text { Latina/Latino }\end{array}$ & 5 & 3.88 & 3 & 3.27 & -0.61 \\
\hline Other & 1 & 5 & 1 & 3.4 & -1.6 \\
\hline White & 122 & 4.07 & 43 & 4.05 & -0.02 \\
\hline
\end{tabular}

Table 3.3: Sense of Belonging Differences based on Fourth Hour Attendance

Based on demographics students that attended Fourth Hour had slightly lower sense of belonging scores in most racial groups. Students that identified as Asian that attended the Fourth Hour on average indicated higher sense of belonging scores. But, due to low sample size it is difficult to prove significant difference statistically.

\subsubsection{Based on Attendance}

This section discusses the question: Is there a relationship between study session attendance and attitude responses? 
Due to small sample size, specifically of students with High Frequency Fourth Hour attendance, it is difficult to prove significant difference statistically. Figure 3.5 depicts a visualization of Sense of Belonging based on Fourth Hour Attendance Frequency. No Frequency had a mean score of 4.05, with Low Frequency 4.00, and High Frequency 3.8. Based on mean scores, the data suggests little to no relationship.

Sense of Belonging based on Fourth Hour Attendance

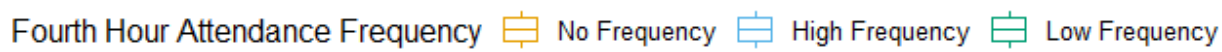

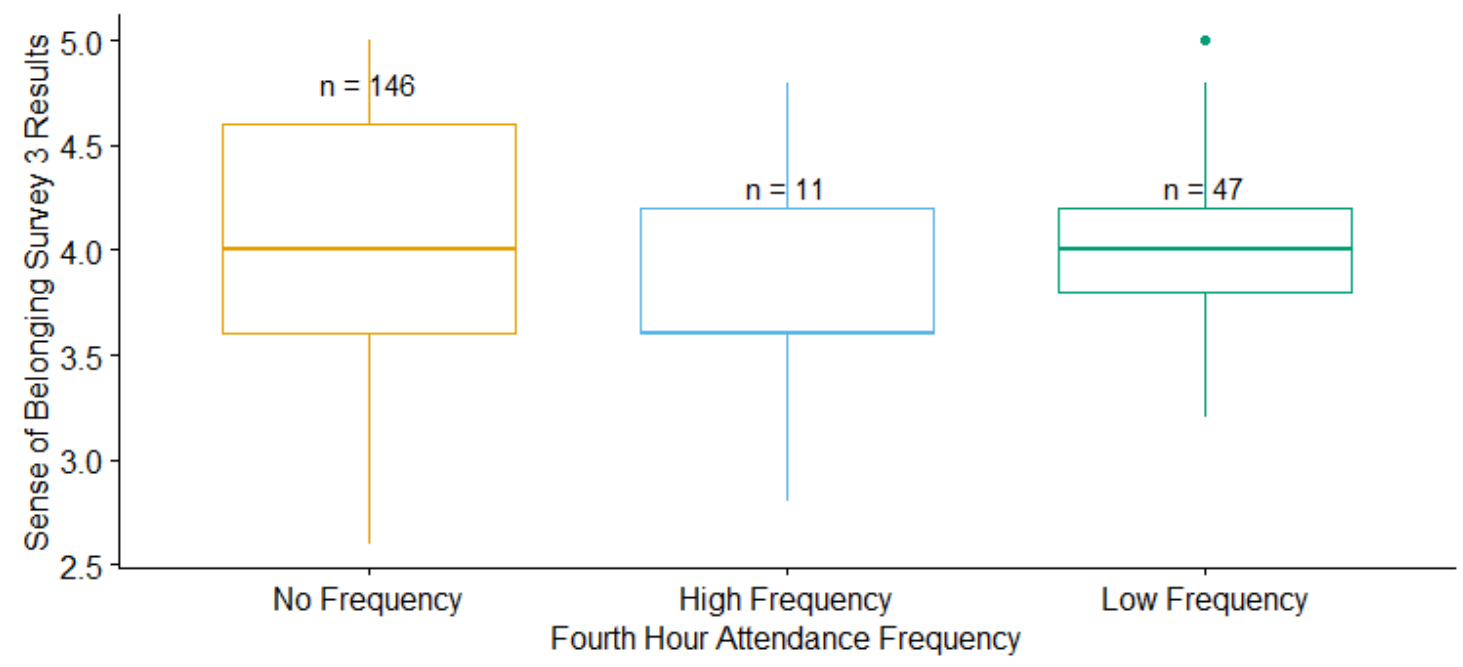

Figure 3.5: Sense of Belonging in CS149 Students based on Fourth Hour Attendance 


\section{Chapter 4: Conclusions and Future Work}

The James Madison University Computer Science Program currently plans on continuing to

offer the study session program in the future for CS149 students. Much of the work done for Fourth Hour has influenced the creation of a CS159 study session program. Fourth Hour materials are publicly available here: https://github.com/mGilbert15/The-Fourth-Hour.

\subsection{Primary Results}

In summary, this study found that:

1. Students who didn't attend Fourth Hour had a greater sense of belonging and learning gains. This result was found to be statistically significant. Future research will explore qualitative gains of students who attended.

2. Students in the minority bracket with no prior programming experience were more likely to attend Fourth Hour than those with experience.

3. Around half of the Black or African American and Hispanic or Latina/Latino populations in CS149 attended the Fourth Hour at least once.

\subsection{Other Results and Observations}

Through discussions with students and teaching assistants, we also found that:

4. Students who attended Fourth Hour frequently felt encouraged. Attendees talked about what to do later in the major and whether or not to repeat CS149 to be 
more successful later. Students asked for TA advice and those struggling in the course that intended to repeat expressed attending sessions helped in understanding topics.

\section{Students who attended Fourth Hour frequently reflected learning material.}

For example they improved performance on PI questions and spoke up that they now "got it". Several students expressed review in Fourth Hour helped them prepare for CS149 assessments. Some indicated attending had a large impact on grade received and aided in improving score on second midterm.

\section{Students encouraged each other, displayed teamwork, and praised team} mates for correct answers. Several students came from different CS149 sections. They often shared techniques they learned in their section to aid in answering questions. Students worked together and often displayed encouraging behavior.

\subsection{Lessons Learned}

Finally, we summarize several lessons learned and key insights to inform future work.

a. Motivation is key Eliminating cost and increasing value of study sessions may help increase Fourth Hour attendance [23]. Publicity, strategies for making it easy for students to attend, incentives for attendance, encouraging students to sign up during CS149 class time, having TAs visit class, having students visit space where sessions are held, and encouraging students to bring friends can be used as techniques to increase student attendance in the future. Extra credit opportunities or snacks/dinner offered during Fourth Hour sessions could be used as tools to increase value of attending Fourth Hour sessions.

According to recent work by Dr. Kenn Barron, cost is a significant factor in motivating students. Cost should be added to the Expectancy-Value model as "a student needs to be free of costs in order to demonstrate motivated behavior" [23]. Spikes in Fourth 
Hour attendance prior to exams depict Fourth Hour value increased for most student prior to exams. Examples of cost for the current Fourth Hour program included time, and fear of self-image (e.g appearing to be behind in class, or not as knowledgeable as other students). Eliminating costs using techniques listed above in addition to instilling a growth mindset in students may increase attendance. Higher attendance numbers are needed both to improve impact and to figure out significance.

b. Struggling students will be the ones to choose to get help and so learning achievements and sense of belonging will be depressed for Fourth Hour compared to students with previous experience who are not underrepresented and find it easy to think of themselves as computer scientists from the beginning.

c. Accounting for previous experience does not completely compensate for item "b." above.

d. Consideration for transforming the study session program into a "1 credit hour support class" similar to the Computational Thinking Lab (CTL) program at MSU would promote consistent attendance [16]. Transforming Fourth Hour into a 1-credit course "recommended to students with limited prior experience or to women or minority groups" similar to CTL could help increase retention and sense of belonging in targeted groups [16]. To reduce resources required for implementation of CTL, the adopted 1-credit course would use materials created for the Fourth Hour, continue to use the PI teaching pedagogy, and utilize the same TA resources in the past. Students would receive course credit for attending Fourth Hour which may increase its value and lower its cost for several students. "When students value something" such as gaining course credit, "they are more likely to do the task" which could increase motivation for students to attend Fourth Hour [23]. 


\section{Bibliography}

[1] "Card Services: Mission, Vision, Values." James Madison University, 26 Mar. 2019, www.jmu.edu/cardctr/mission.shtml.

[2] "What Is the S\&E Retention Rate in U.S. 4-Year Institutions?" STEM Education Data and Trends, 2014, www.nsf.gov/nsb/sei/edTool/data/college-10.html.

[3] Michael S. Kirkpatrick , Chris Mayfield, Evaluating an Alternative CS1 for Students with Prior Programming Experience, Proceedings of the 2017 ACM SIGCSE Technical Symposium on Computer Science Education, March 08-11, 2017, Seattle, Washington, USA [doi:10.1145/3017680.3017759].

[4] DuBow, Alexis, et al. "Multiple Factors Converge to Influence Women's Persistence in Computing: A Qualitative Analysis." Best of Respect 2016, 1 May 2017, www.ncwit.org/sites/default/files/resources/computingmay2017_multiple_factors _converge_to_influence_womens_persistence_in_computing.pdf.

[5] "Top 10 Ways You Can Retain Students in Computing." National Center for Women \& Information Technology, National Center for Women \& Information Technology, www.ncwit.org/resources/top-10-ways-you-can-retain-students-computing/top-10ways-you-can-retain-students.

[6] Eberlein, T. (2012). Beneficial effects of PLTL persist to later courses at Penn State Schuylkill. Peer-Led Team Learning: Evaluation. Online at http://www.pltlis.org. Originally published in Progressions: The Peer-Led Team Learning Project Newsletter, Volume 6, Number 1, Fall 2004.

[7] Louis Deslauriers, Logan S. McCarty, Kelly Miller, Kristina Callaghan, Greg Kestin, 2019. Measuring actual learning versus feeling of learning in response to being actively engaged in the classroom, Proceedings of the National Academy of Sciences Sep 2019, 116 (39) 19251-19257; doi: 10.1073/pnas.1821936116.

[8] PLTLIS, "Peer-Led Team Learning International Society," Peer-Led Team Learning International Society, 2018, pltlis.org/.

[9] Eberlein, Thomas et al. "Pedagogies of engagement in science: A comparison of PBL, POGIL, and PLTL*." Biochemistry and molecular biology education : a bimonthly publication of the International Union of Biochemistry and Molecular Biology vol. 36,4 (2008): 262-273. doi:10.1002/bmb.20204. 
[10] Moog, Richard S., Frank J. Creegan, David M. Hanson, James N. Spencer, and Andrei R. Straumanis, 2006. Process-Oriented Guided Inquiry Learning: POGIL and the POGIL Project, Metropolitan Universities Journal, v. 17, pp. 41-51.

[11] L. Williams, D. S. McCrickard, L. Layman, and K. Hussein, "Eleven Guidelines for Implementing Pair Programming in the Classroom," in Agile 2008 Conference, Agile, 2008. AGILE '08. Conference. EBSCOhost, 2008, p. 445, doi:10.1109/Agile.2008.12.

[12] P. Leo, "Success in Introductory Programming," Communications of the ACM, vol. 56, no. 8, 2013, doi:10.1145/2492007.2492020.

[13] Z. Daniel and L. Porter, "Peer Instruction in Computing: The Value of Instruction Intervention," Computers \& Education, vol. 71, pp. 87-96, 2014, doi:10.1016/j.compedu.2013.09.015.

[14] Cynthia Taylor, Jaime Spacco, David P. Bunde, Andrew Petersen, Soohyun Nam Liao, and Leo Porter, "A Multi-Institution Exploration of Peer Instruction in Practice," Proceedings of the 23rd Annual ACM Conference on Innovation and Technology in Computer Science Education - ITiCSE 2018, 2018, doi:10.1145/3197091.3197144.

[15] Ryder, B.G., Hari, P. (2012). Peer-Led Team Learning Computer Science: Module 1: Introduction to Computer Science. Online at http://www.pltlis.org. Originally published in Progressions: The Peer-Led Team Learning Project Newsletter, Volume 9, Number 1, Fall 2007.

[16] Laura Kay Dillon and Michelle Slattery. "A Flipped Active-learning Class to Support Diverse Students in a Large Introduction to Programming Class". 2018 ASEE Annual Conference 86 Exposition, Salt Lake City, Utah, 2018, June. ASEE Conferences, 2018. https://peer.asee.org/29677 Internet. 08 Apr, 2020.

[17] Dillon, Laura K. "Computer Science and Engineering Computational Thinking Lab." CSE CTL, www.cse.msu.edu/ ldillon/cse-ctl/.

[18] Wash, P.D. (2014). Taking advantage of mobile devices: Using Socrative in the classroom. Journal of Teaching and Learning with Technology, 3(1), 99-101.[doi: 10.14434.jotlt.v3n1.5016].

[19] "Home." Socrative, Showbie Inc, 2020, socrative.com/.

[20] Kaczmarczyk, Lisa \& Petrick, Elizabeth \& East, J. \& Herman, Geoffrey. (2010). Identifying student misconceptions of programming. SIGCSE'10 - Proceedings of the 41st ACM Technical Symposium on Computer Science Education. 107-111. [doi: 10.1145/1734263.1734299].

[21] Kassambara, Alboukadel. "Unpaired Two-Samples Wilcoxon Test in R." STHDA, Academic Theme for Hugo, 2017, www.sthda.com/english/wiki/unpaired-two-sampleswilcoxon-test-in-r. 
[22] Kassambara, Alboukadel. "Paired Samples T-test in R" STHDA, Academic Theme for Hugo, 2017, www.sthda.com/english/wiki/paired-samples-t-test-in-r.

[23] Barron, K. E., \& Hulleman, C. S. (2015). Expectancy-Value-Cost model of motivation. In J.D. Wright (Ed.), International encyclopedia of the social 8 behavioral sciences, 2nd ed (Vol. 8, pp. 503-509). Oxford: Elsevier. doi:10.1016/B978-0-08-097086-8.26099-6. 


\section{Appendix}

\section{A.1 List of Data Collected}

Quizzes

- Pre-Core Assessment (10 MC, 10 pts)

- Post-Core Assessment(10 SA, 30 pts)

- CS 159 (CS 1.5) retention quiz (40 pts)

Fourth Hour

- Number of times attended

- Date of first time attended

- Indicates if attended week 4, 9, 14 (weeks before exams)

Part 1 Survey

- Demographics

- Prior programming experience

- Confidence/Interest

- Sense of Belonging (5 Q's)

Part 2 Survey

- Sense of Belonging (30 Q's)

- Including same Sense of Belonging (5 Q's)

Part 3 Survey

- Self-Efficacy

- Teamwork

- Sense of Belonging (5 Q's) 
Exams

- Exam1 - written and coding (100 pts)

- Exam2 - written and coding (100 pts)

- Exam3 - written and coding (100 pts)

- Class attendance (low/med/high)

- Homework score (low/med/high)

Other

- Section/Instructor

- Status (e.g., withdrawn)

\section{A.2 Attitudinal Surveys}

Each survey was one sheet of paper front and back. Surveys were administered and gathered by the data collector during student class time.

- Part 1: Demographics, Experience, Confidence

- Part 2: Sense of Belonging (all 30 items)

- Part 3: Self-Efficacy, Teamwork Perceptions 
Page 1

\section{CS 149 Student Survey - Part 1}

Name:

Email: @dukes.jmu.edu

Please help us learn more about the impact of this class on your interest in computer science by completing the following questions. There are no right or wrong answers; we are interested in your honest reactions and opinions.

This survey is part of the research study for which you have previously given consent. (If you did not give consent, you do not need to complete this survey.) As a reminder, you will have the opportunity to win a $\$ 25$ gift card if you complete all three surveys.

If you have any questions about the research study or wish to withdraw, please contact Dr. Mayfield $<$ mayfiecs@jmu.edu>. Thank you!

\section{Instructions}

For each question, please indicate your answer this way:

To make a correction, fill in the previous box completely:
A $\quad$ B $\quad$ C $\quad$ D $\quad$ E

凶 $\square \quad$ Answer $=C$

Answer $=D$

\section{Background}

Major(s):

Minor(s):

Year at JMU:

Graduation (month \& year):

Prior to taking this course, have you had any programming experience? (e.g., Java, Python, Scratch)

$\square$ Yes $\quad \square$ No

If yes, mark all that apply. Please also write the programming language(s) to the right of each course.

$\square$ AP Computer Science A (Java) or equivalent

$\square$ AP Computer Science Principles or equivalent

$\square$ Other high school Computer Science course(s)

$\square$ Summer camp(s) or other short-term course(s)

$\square$ Learned programming on your own (e.g., websites)

$\square$ Already took CS 149 at JMU and retaking it this term

$\square$ Other programming courses at JMU (e.g., CIS, ISAT) 
Page 2

\section{Confidence}

How confident are you in your programming abilities?

\begin{tabular}{|c|}
\hline $\begin{array}{l}- \text { Very } \\
\text { confident }\end{array}$ \\
\hline
\end{tabular}

How confident are you that you will do well in this course?

\begin{tabular}{|c|c|}
\hline $\begin{array}{l}\square \text { Very } \\
\text { confident }\end{array}$ & $\begin{array}{c}\square \text { Moderately } \\
\text { confident }\end{array}$ \\
\hline
\end{tabular}

Are you interested in taking more computer science courses?

$\begin{array}{ccccc}\square \text { Definitely } & \square \text { Probably } & \square \text { Might or } & \square \text { Probably } & \square \text { Definitely } \\ \text { yes } & \text { yes } & \text { might not } & \text { not } & \text { not }\end{array}$

In this computer science class...

Strongly

Disagree

Disagree Neutral

Agree

Strongly

I feel that I belong to the computer science community.

I feel accepted.

I feel like an outsider.

I try to say little as possible.

I trust my instructors to be committed to helping me learn.

\section{Demographics}

Age

$\square 18-20$

$\square 21-24$

$\square>24$

Pronouns

$\square \mathrm{He} / \mathrm{Him} / \mathrm{His} \quad \square$ She/Her/Hers $\quad \square$ They/Them/Theirs $\square$ Other:

Race and/or ethnicity (mark all that apply)

$\square$ American Indian or Alaska Native

$\square$ Black or African American

$\square$ Native Hawaiian or Pacific Islander

$\square$ Other:
Asian

Hispanic or Latina/Latino

$\square$ White 
Page 1

\section{CS 149 Student Survey - Part 2}

Name:

Email:

@dukes.jmu.edu

Please help us learn more about the impact of this class on your interest in computer science by completing the following questions. There are no right or wrong answers; we are interested in your honest reactions and opinions.

This survey is part of the research study for which you have previously given consent. (If you did not give consent, you do not need to complete this survey.) As a reminder, you will have the opportunity to win a $\$ 25$ gift card if you complete all three surveys.

If you have any questions about the research study or wish to withdraw, please contact Dr. Mayfield $<$ mayfiecs@jmu.edu>. Thank you!

\begin{tabular}{|c|c|c|c|}
\hline Instructions & A $\quad$ B $\quad$ C $\quad$ D & $\mathrm{E}$ & \\
\hline For each question, please indicate your answer this way: & $\square \square \bigotimes \square$ & $\square$ & Answer $=C$ \\
\hline
\end{tabular}

In this computer science class...

Strongly

Disagree
Disagree

Neutral

Agree

Strongly Agree

I feel that I belong to the computer science community.

I consider myself a member of the computer science world.

I feel like I am part of the computer science community.

I feel a connection with the computer science community.

I feel like an outsider.

I feel accepted.

I feel respected.

I feel disregarded.

I feel valued.

I feel neglected.

I feel appreciated.

I feel excluded.

I feel like I fit in.

I feel insignificant. 
Page 2

In this computer science class...

I feel at ease.

I feel anxious.

Even when I do poorly, I trust my instructors to have faith in my potential.

I trust my instructors to be committed to helping me learn.

Strongly

Disagree
Disagree
Neutral

Agree

Strongly

Agree

I have trust that I do not have to constantly prove myself.

I feel comfortable.

I feel tense.

I feel nervous.

I feel content.

I feel calm.

I feel inadequate.

I wish I could fade into the background and not be noticed.

I try to say little as possible.

I enjoy being an active participant.

I wish I were invisible.

I trust the testing materials to be unbiased. 
Page 1

\section{CS 149 Student Survey - Part 3}

Name:

Email: @dukes.jmu.edu

Please help us learn more about the impact of this class on your interest in computer science by completing the following questions. There are no right or wrong answers; we are interested in your honest reactions and opinions.

This survey is part of the research study for which you have previously given consent. (If you did not give consent, you do not need to complete this survey.) As a reminder, you will have the opportunity to win a $\$ 25$ gift card if you complete all three surveys.

If you have any questions about the research study or wish to withdraw, please contact Dr. Mayfield $<$ mayfiecs@jmu.edu>. Thank you!

\section{Instructions}

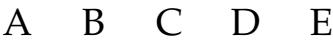

For each question, please indicate your answer this way: $\square \square \square \square \square \quad$ Answer=C

To make a correction, fill in the previous box completely: $\square \square \square$ ( $\square \square$ Answer=D

Please choose how true each statement is of you when learning computer science.

\begin{tabular}{|c|c|c|c|}
\hline $\begin{array}{c}1:: \text { Not } \\
\text { at all } \\
\text { true of } \\
\text { me }\end{array}$ & 2 & $\begin{array}{c}3:: \\
\text { Some- } \\
\text { what } \\
\text { true of } \\
\text { me }\end{array}$ & 4 \\
\hline
\end{tabular}

I believe I will receive an excellent grade in this class.

I'm certain I understood the most difficult material presented in the readings for this course.

I'm confident I understood the basic concepts taught in this course.

I'm confident I understood the most complex material presented by the instructor in this course.

I'm confident I did an excellent job on the assignments and tests in this course.

I expect to do well in this class.

I'm certain I mastered the skills being taught in this class.

Considering the difficulty of this course, the teacher, and my skills, I think I did well in this class. 
Page 2

Please choose how much you agree with each statement.

Strongly

Disagree
Disagree

$\mathrm{N}$

I find working as part of a team in courses to be a valuable experience.

Teams in courses work well together.

I find teamwork to be a productive use of course time.

I find that teams help me learn course material more than if I just studied alone.

I learn more in courses where I have been a member of a team.

I find being part of a team improves my course grades.

I find that working with a team helps me develop skills in working with others.

I find that working with a team helps me develop more respect for the opinions of others.

I find that working with a team enhances my sense of who I am.

I find that being on a team helps me become better at problem solving.

Being part of a team discussion improves my ability to think through a problem.

I feel that working in teams improves my critical thinking skills.

I find that teams make good decisions.

In this computer science class...

Strongly

Disagree

Disagree

Neutral

Agree

Strongly

I feel that I belong to the computer science community.

I feel accepted.

I feel like an outsider.

I try to say little as possible.

I trust my instructors to be committed to helping me learn. 


\section{A.3 Curriculum Guide}

Interested in implementing the Fourth Hour program? The following serves as a guide for the Java based study session curriculum:

\section{Accessing Materials}

(a) Go to https://github.com/mGilbert15/The-Fourth-Hour

(b) Clone or Download the learning materials onto your personal device

\section{Understanding Material Organization}

(a) Materials for each week are broken down into folders labeled accordingly (we will refer to them as modules).

(b) Each module will contain a PowerPoint.

(c) Some modules will contain supplementary worksheets.

i. Modules with worksheets or activities that are not self-explanatory will contain an explanation guide.

ii. Prior to the session make sure to print enough supplementary worksheets activities for students. PRINT SINGLE SIDED.

(d) The Socrative Quiz Links document contains information on accessing the Socrative quizzes and creating a free Socrative account.

\section{Implementation}

(a) Prior to holding sessions, advertise the program to targeted students.

(b) Refer to Chapter 2 for information on how to structure sessions, a session schedule, and how to implement Peer Instruction Questions.

(c) Ensure TAs presenting material have looked over module slideshow prior to each session andsolve slideshow problems on whiteboard if possible to engage students. 


\section{A.4 Reference Code}

\section{A.4.1 Learning Retention Graphs}

The following code corresponds to the creation of Figures 3.2 and 3.3 given the data from this study. The statistical analysis process is included.

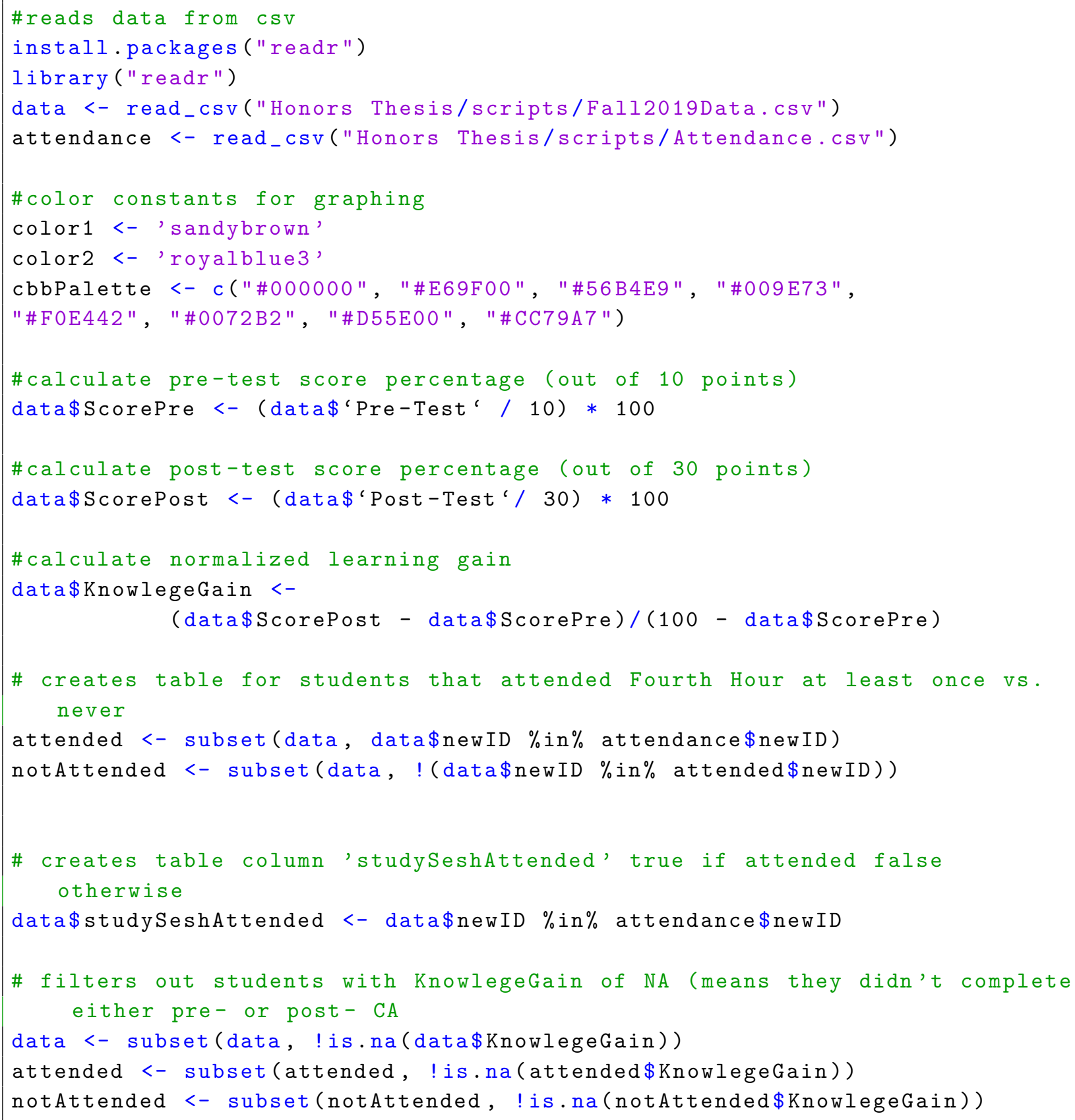


77

83

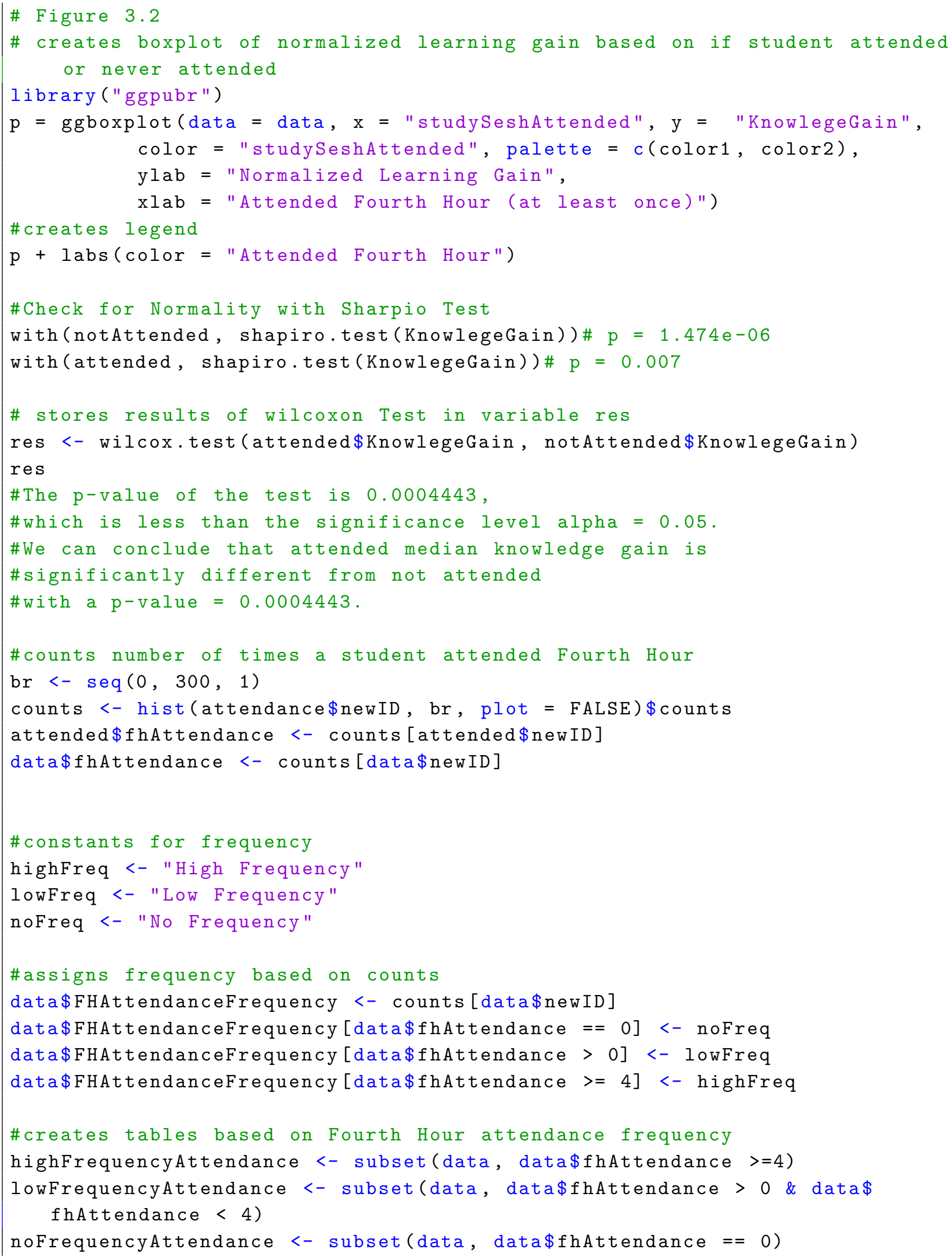




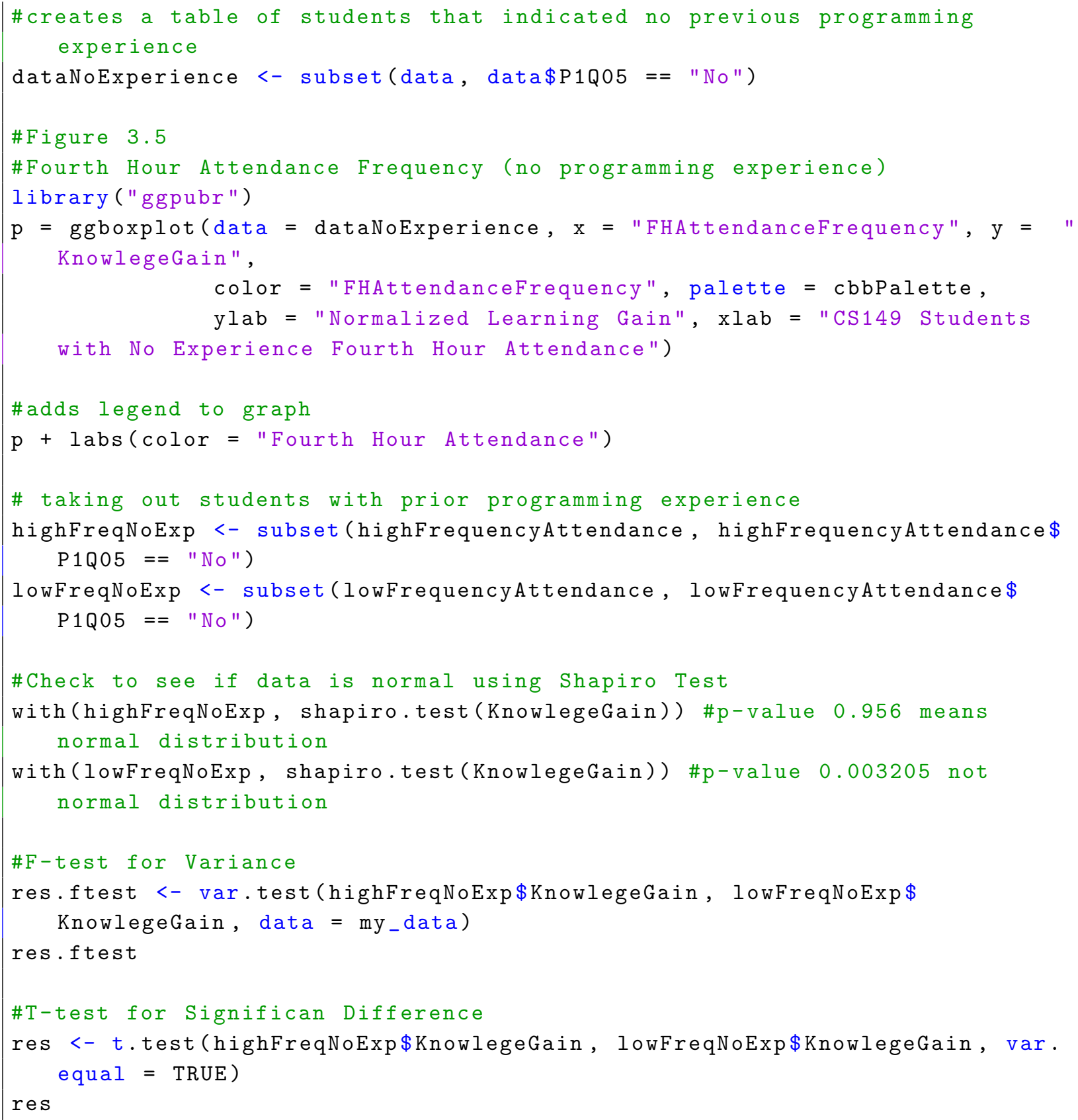




\section{A.4.2 Sense of Belonging Graphs}

The following code corresponds to the creation of Figures 3.4 and 3.5 given the data from this study.

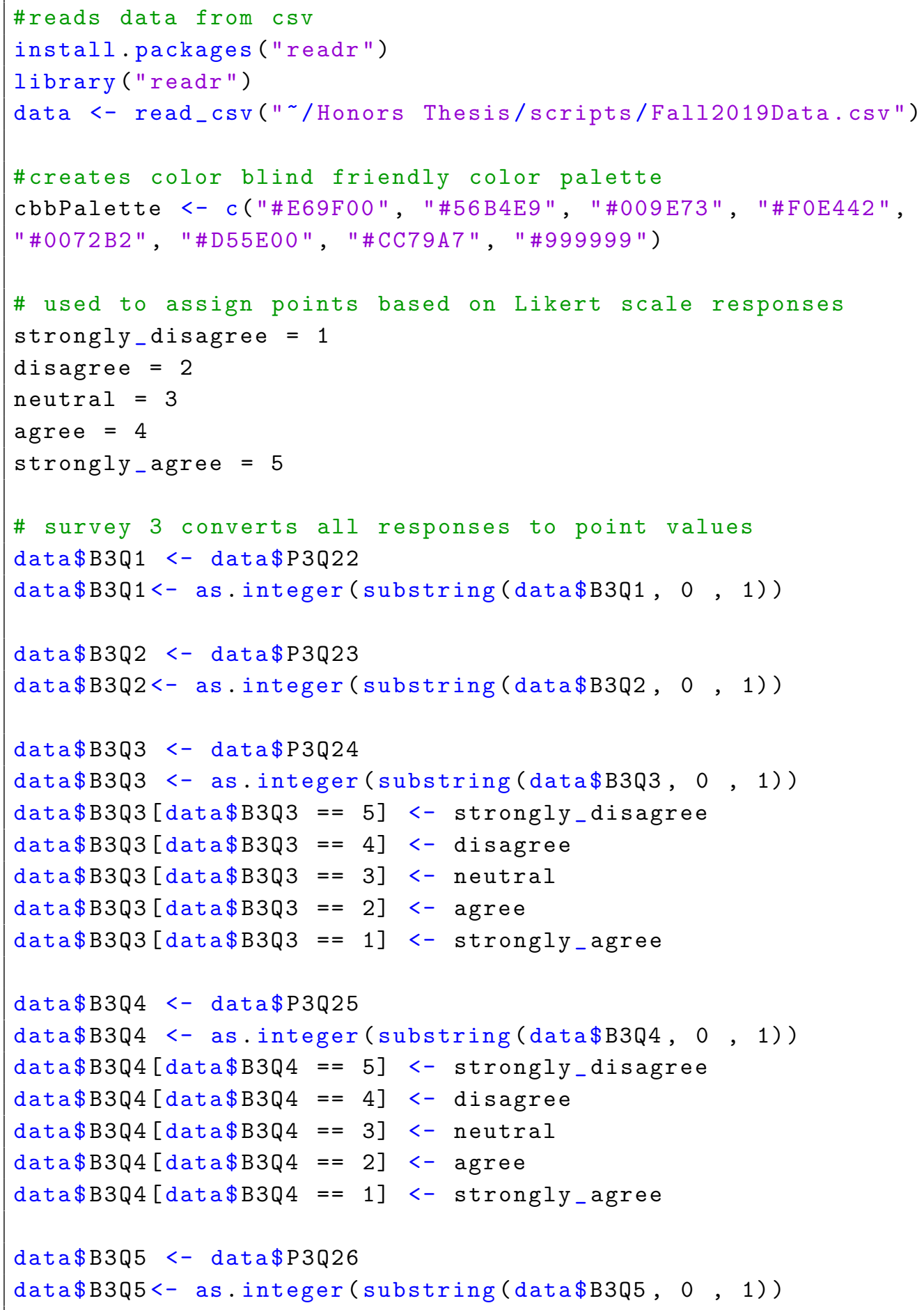




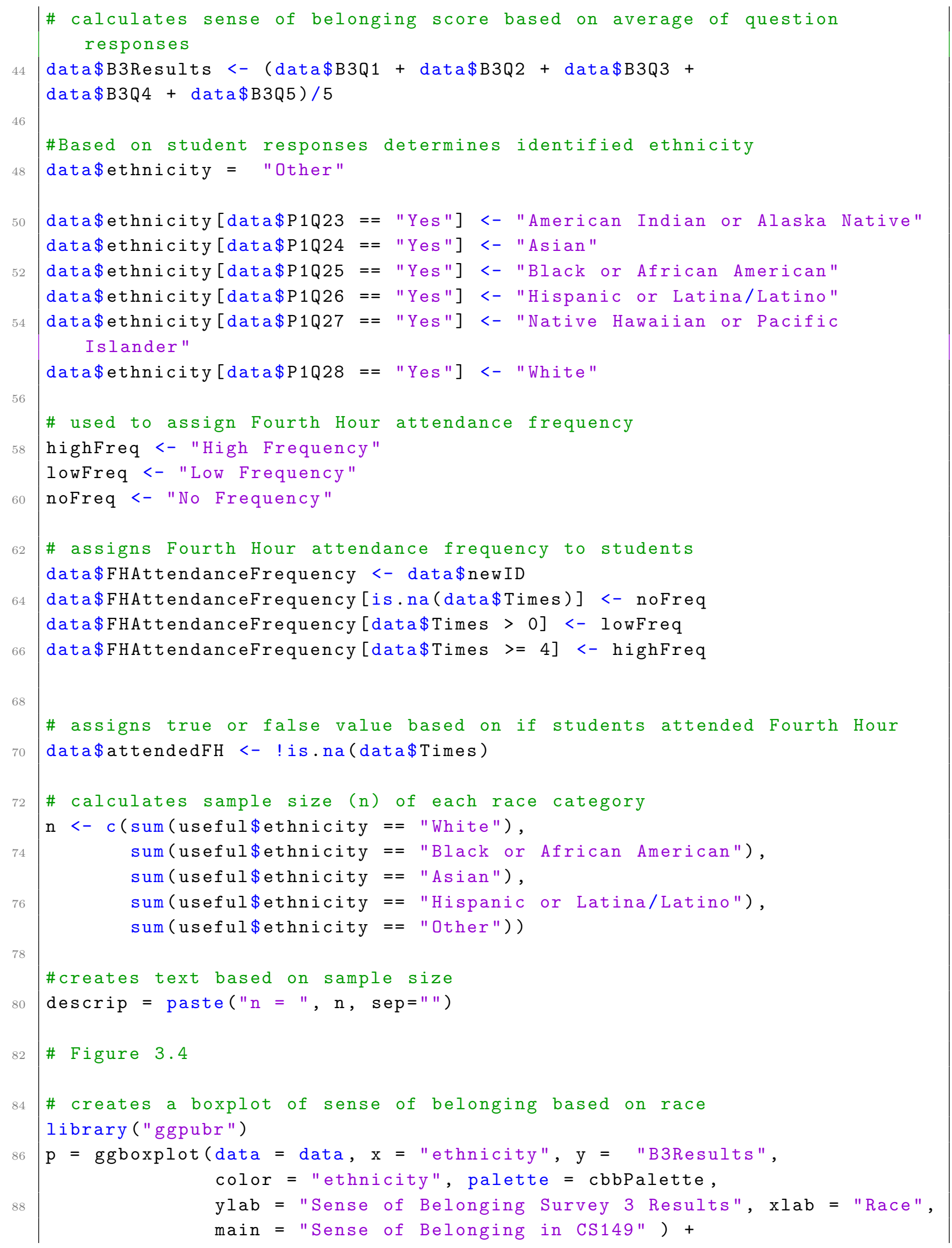




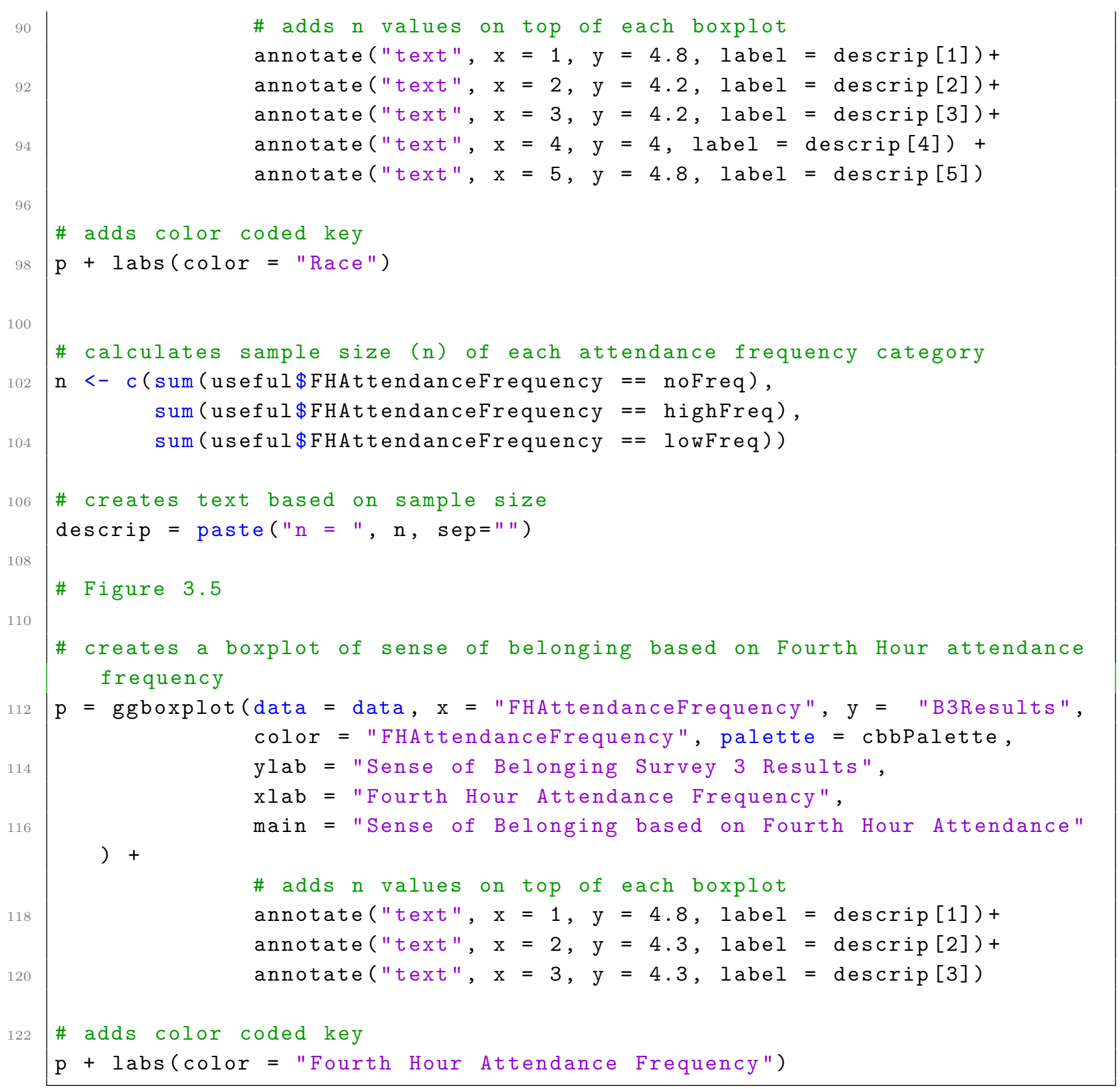

